\title{
Removal of Color Pigments From Corn Distillers Dried Grains With Solubles (DDGS) to Produce an Upgraded Food Ingredient
}

\author{
J. A. Saunders ${ }^{1}$, Kurt A. Rosentrater ${ }^{2}$ \& P. G. Krishnan ${ }^{1}$ \\ ${ }^{1}$ South Dakota State University, United States \\ ${ }^{2}$ Iowa State University, United States \\ Correspondence: Kurt A. Rosentrater, Department of Agricultural and Biosystems Engineering, Iowa State \\ University, 3167 NSRIC Building, Ames, IA, 50011, United States. Tel: 1-515-294-4019. E-mail: \\ karosent@iastate.edu
}

Received: August 6, 2013 Accepted: August 30, 2013 Online Published: September 2, 2013

doi:10.5539/jfr.v2n5p111 URL: http://dx.doi.org/10.5539/jfr.v2n5p111

\begin{abstract}
Processing steps including bleaching, deodorizing, and milling are imperative for improving the functionality of distillers grains in various food matrices, as well as improving consumer acceptance. Utilization of distillers grains in food products is of particular interest. Various parameters were explored for the removal of pigments, including raw DDGS (diameter 0.384$)$ or milled DDGS $(0.329 \mathrm{~mm})$, number of extractions $(1,2$, or 3$)$, time ( 30 , 60 , or $90 \mathrm{~min}$.), and ethanol concentration $(5,10$, or $15 \mathrm{~mL} / \mathrm{g})$. Altogether, the experimental design was a $2 \times 3 \times$ $3 \times 3$ factorial, resulting in 54 trials, which were each replicated twice. Physical and chemical properties of the resulting DDGS were analyzed. Protein content was impacted by time and number of extractions. A decrease in lipid content resulted in an inverse increase in protein content. Lipid and pigment analysis showed similar decreasing trends, signifying that lipid contents decreased while increasing solvent extraction time, ethanol concentration, and number of extractions. Physical property analysis showed ethanol extraction to be a moderately effective bleaching technique for DDGS. Chemical property data showed that the treatments were extremely effective in reducing lipid and pigment values, while increasing protein. Effective removal of pigments can improve the color of food products containing DDGS, which can lead to greater consumer acceptability of this ingredient.
\end{abstract}

Keywords: ethanol, coproducts, DDGS, pigment, removal

\section{Introduction}

Corn-based ethanol production is escalating exponentially in order to satisfy consumer demands for energy and increasing urgency to create reliable renewable fuel resources for the United States. Much research is being pursued in order to establish value for fuel ethanol and its co-products: distillers grains and carbon dioxide. There has been enormous growth in the bioethanol industry in the last decade due to strong interest in alternative fuels, and therefore, there is now substantial distillers dried grains with solubles (DDGS) production. The production of DDGS in 2009-2010 was calculated to be around 30.5 million metric tons, and is projected to have grown to nearly 43 million metric tons during 2012 (RFA, 2013).

Commercial ethanol production is accomplished using one of two methods: dry grind or wet milling. The dry grind process is discussed in depth by Dien et al. (2003), Jaques et al. (2003), and Liu and Rosentrater (2011). This process does not fractionate the entire corn kernel, and thus requires less equipment and capital compared to wet milling processes. One benefit of dry-grind processing is that many plants are producer-owned and directly benefit surrounding rural communities (Rausch \& Belyea, 2006). Figure 1 shows a flow diagram depicting typical dry-grind processing in a manufacturing plant. Wet milling is a more capital and equipment intensive process. The corn kernel is fractionated into different components, thereby resulting in many co-products. Typically, large volumes of ethanol are produced, mostly through corporate owned distilleries and processors. Presently, the use of distillers grains co-products has been limited to livestock feed, while carbon dioxide is either distributed to beverage companies or released into the atmosphere. Other co-product concepts for utilizing distillers grains included plastics, bio diesel, and human food products. Utilization of distillers grains in food products is of particular interest due to altered nutritional content post ethanol production. In fact, numerous research studies have been conducted in order to analyze nutritional content including Belyea et al. (2004), Liu 
and Rosentrater (2011), Shurson et al. (2004), and Spiehs et al (2002). Rosentrater and Muthukumarappan (2006) reported typical ranges for chemical properties of DDGS, including protein of $26.8-33.7 \%$, fat of $3.5-12.8 \%$, carbohydrates of 39.2-61.9\%, and total dietary fiber of $24.2-39.8 \%$.

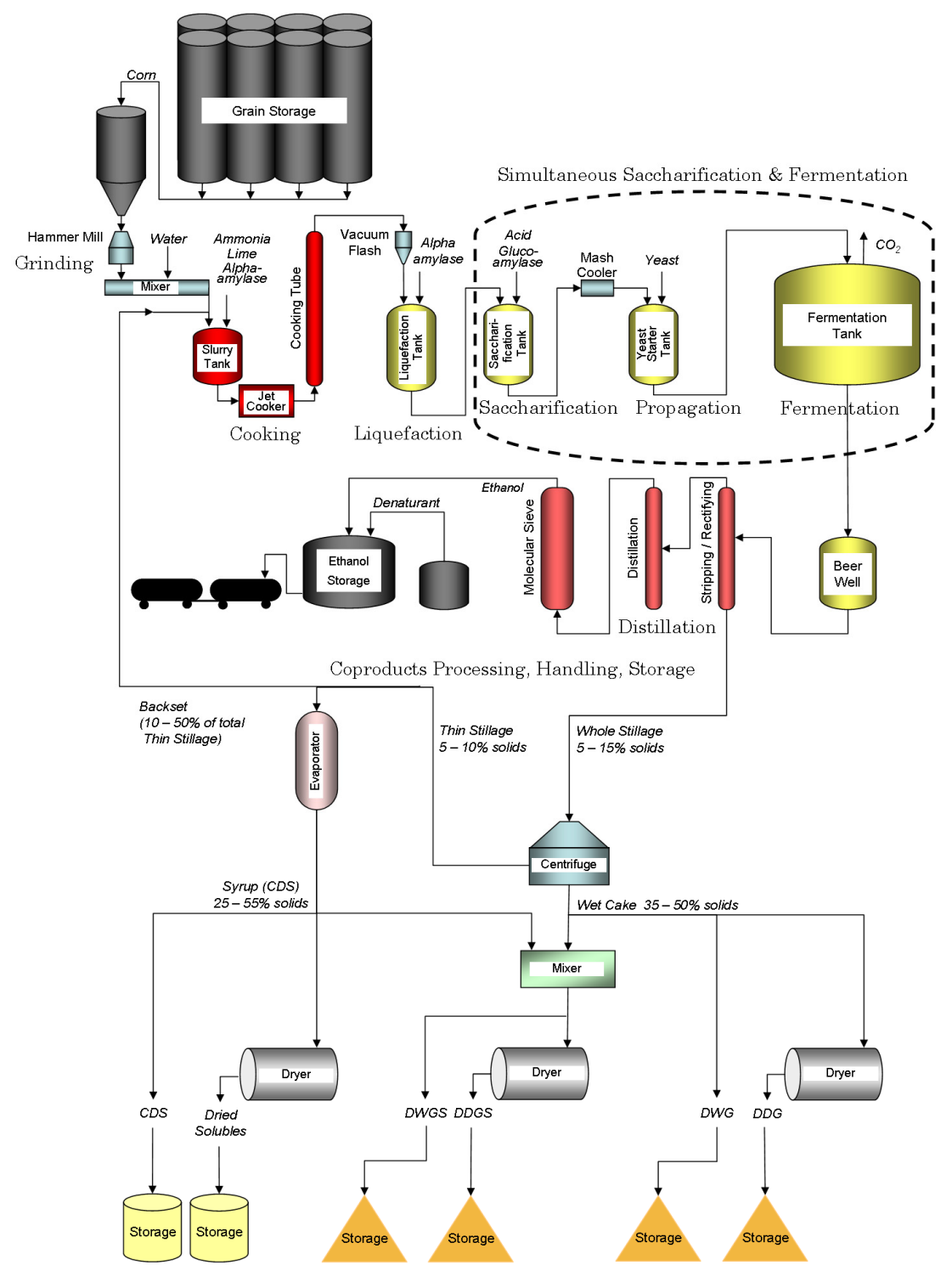

Figure 1. Process flow diagram for a typical dry-grind corn-to-ethanol manufacturing plant commonly used in the U.S. ethanol industry

Individuals diagnosed with medical conditions, such as diabetes or celiac diseases, may benefit from food products created from DDGS, as it is a low starch, high protein, and gluten-free material. Additionally, there are an increasing number of non-celiac, gluten-sensitive individuals. This ingredient thus meets the specifications for these types of diets. Consumer markets welcome food products that can offer variety into the diet for these special medical conditions. Short-term studies completed by Arora and McFarlane (2005) concluded that a low carbohydrate diet resulted in lower HbA1c levels $(7.6(+/-0.3) \%)$, greater glycemic control, lower postprandial glucose levels, and improved insulin sensitivity. Distillers grains offer a low starch material that could be processed into practical food products for diabetic populations. Foods higher in starch increased postprandial glucose levels and insulin needs. For the most part, an insulin dependent diabetic would need to use an increased quantity of insulin injected, while a non-insulin dependent diabetic would need to restrict the quantity of high starch foods consumed. 
Celiac diseases, and other gluten sensitivities, on the other hand, are categorized by sensitivity to gluten, which is a protein in wheat, rye, oats and barley. The restrictive nature of this disease negatively impacts quality of life. Approximately 1 in 133 persons in the United States are diagnosed with some form of this condition (Mahan \& Escott-Stump, 2004). This phenomenon is not confined to the U.S.; in fact, this trend is growing globally. A study completed by Lee and Newman (2003) concluded that $86 \%$ of survey respondents who had this diagnosis considered themselves to be negatively impacted on their ability to dine out. Therefore, patients with either of these restrictive medical conditions would benefit from DDGS products being introduced into the food market.

Before DDGS can be incorporated into food products, this fibrous material must be improved in order to be both visually and functionally appealing to consumers. Some potential processing steps for DDGS include bleaching, deodorizing, and milling. As discussed in Liu and Rosentrater (2011), these steps are imperative for improving the functionality of DDGS in various food matrices, as well as improving consumer acceptance of such food products. However, these types of operations may alter the nutrient content of the DDGS.

To date, many studies have been completed concerning the removal of oil from raw corn (Chang et al., 1995; Chen \& Hoff, 1987; Chien et al., 1988; Chien et al., 1990; Hojilla-Evangelista et al., 1992). However, very little research has been completed on extraction of oil from DDGS. Singh and Cheryan (1998) investigated oil extraction from DDGS and recovery of the valuable oils. Their belief was that removing oil from DDGS would add extra value to corn without degrading market value of the remaining DDGS since it was chiefly sold on behalf of its high fiber and protein content. Use of ethanol as an extraction solvent proved efficient in the removal of oil. Ratios of 2, 4, and 6 ethanol-to-DDGS $(\mathrm{mL} / \mathrm{g})$ proved effective in extracting up to $50 \%$ of oils. Extraction rates were not accelerated for ratios above 6. Saunders and Rosentrater (2009) examined physical properties of DDGS which had been subjected to hexane extraction. They found that the resulting DDGS had water activity, thermal properties, bulk density, and angle of repose values similar to raw, unextracted DDGS. Color values were substantially lighter ( $\mathrm{L}$ values were as high as 56.69$)$, however, and fat levels $(2.7 \% \mathrm{db})$ were much lower.

A review of potential bleaching techniques has been published (Saunders et al., 2007). Little actual work in this area has been done with corn co-product streams. A study completed by Park et al. (1997) indicated that carotenoids in corn gluten meal (CGM) could be eliminated via extraction with ethanol and butanol. Extractions were completed with wet corn gluten meal and $150 \mathrm{~mL}$ of ethanol or butanol that was stirred for 15 minutes at room temperature and then filtered once. The remaining slurry was suspended in an additional $100 \mathrm{~mL}$ of ethanol or butanol, stirred for $15 \mathrm{~min}$ at room temperature, and then filtered a second time. Results indicated that carotenoids in CGM were rapidly extracted into ethanol, with no additional increase in carotenoid extraction after 5 minutes of stir time. In contrast, butanol extracts gradually increased the absorbance of carotenoids for up to 1-hr stir time. The difference in extraction rates is readily explained by CGM having a greater dispersibility in ethanol. Surface area contact can be improved with vigorous agitation thus resulting in enhanced carotenoid extraction. Total solid loss after the second filtration was greater with butanol $(24 \%)$ than ethanol $(11 \%)$. The majority of solid loss occurred after the first extraction.

Use of ethanol to extract pigments is a potential technique for bleaching of DDGS, but has not yet been investigated (Saunders et al., 2007). To date, no work has examined the effect of oil and carotenoid extraction from DDGS. Therefore, the objective of this research was to examine the effectiveness of color reduction for DDGS pigments and carotenoids through ethanol extraction.

\section{Materials and Methods}

\subsection{Sample Preparation}

The distillers dried grains with solubles (DDGS) utilized in this study was collected from a commercial dry grind ethanol plant. Two distinct particle sizes of DDGS were used. One stream was raw DDDGS, which had a mean particle diameter of $0.384 \mathrm{~mm}$, while the second stream was milled in a Cyclone sample mill (UDY Corporation, Fort Collins, CO, USA), resulting in a mean particle diameter of $0.329 \mathrm{~mm}$.

\subsection{Extraction}

Independent variables in this study included particle size (diameter of raw DDGS was 0.384; diameter of milled DDGS was $0.329 \mathrm{~mm})$, number of extractions $(1,2$, or 3$)$, agitation time $(30,60$, or $90 \mathrm{~min})$, and concentration of ethanol $(5,10$, or $15 \mathrm{~mL} / \mathrm{g}$ of dry DDGS). The completely randomized design (CRD) was a $2 \times 3 \times 3 \times 3$ factorial analysis, resulting in 54 trials, replicated twice, which thus totaled 108 experimental runs.

Extractions were conducted at room temperature $\left(\sim 25^{\circ} \mathrm{C}\right)$. For each treatment combination, approximately $20 \mathrm{~g}$ of ground DDGS were placed in an $800-\mathrm{mL}$ beaker. Varying amounts of ethanol were then added to the sample, 
depending on the ethanol-to-DDGS concentration ratio (e.g., for $5 \mathrm{~mL} / \mathrm{g}$ concentration, $100 \mathrm{~mL}$ ethanol was added; for $10 \mathrm{~mL} / \mathrm{g}, 200 \mathrm{~mL}$ ethanol was added; and for $15 \mathrm{~mL} / \mathrm{g}, 300 \mathrm{~mL}$ ethanol was added to the sample). DDGS slurries were agitated by a large sized magnetic stir rod for varying amounts of time (30,60, or 90 min). Then the number of extractions varied between 1,2, or 3 . Ethanol containing soluble pigments, carotenoids, and oils were then decanted from the slurry using a $10-\mathrm{mL}$ syringe.

Once slurry extractions were finished, all treatment combinations were subjected to a water wash, which consisted $100 \mathrm{~mL}$ of distilled water for $15 \mathrm{~min}$, while being continuously agitated via a large magnetic stir rod. Upon completion of the water wash, samples were centrifuged (model 100 Precision Durafuge, Winchester, VA) in 80-mL containers at 4,000 RPM for $5 \mathrm{~min}$. Centrifugation allowed the DDGS to settle to the bottom of each container, so that water, pigments, carotenoids, and lipids could be removed.

Treated DDGS was then removed from the centrifuge containers and transferred into aluminum moisture dishes (75 mm diameter and $25 \mathrm{~mm}$ high), and were evenly spread out to cover the entire container in order to optimize surface area and equalize drying rates. Samples were then dried at $45{ }^{\circ} \mathrm{C}$ for 24 hours in a laboratory oven (Thelco Precision, Jovan Inc., Wincester, VA). Once dry, the samples were transferred into a desiccator for cooling for one hour. The extracted DDGS samples were then ground in a laboratory mill (Proctor Silex, Southern Pines, NC) until agglomerated particle clumps were broken apart. Each sample was then subjected to chemical and physical analysis.

\subsection{Color Analysis}

Color was measured using a spectrocolorimeter (LabScan XE, Hunter Associates Laboratory, Reston, VA) with Hunter L-a-b opposable color scales (Hunter Associates Laboratory, 2002).

\subsection{Chemical Analysis}

Crude protein, crude lipid, and total pigment levels were determined. Protein analysis was completed using CE Elantech Flash EA 1112 (ThermoFinnigan Italia S.p.A., Rodano (MI) Italy), following the crude protein-combustion method 46-30 (AACC, 2000). Lipid analysis was completed using Official method 920.39 (AOAC, 2003) with slight modifications: alterations to the method included the use of petroleum ether for 4 hours with a condensation drop rate of 5-6 drops/sec, samples were then dried overnight at room temperature under a ventilated hood. Finally, pigment extraction analysis utilized AACC Method 14-50 (2000) modified to use drying the samples for 24 hours, thus decreasing moisture content to less than $1 \%$.

\subsection{Statistical Analysis}

Statistical analyses on all collected data were performed via SAS v.8.0 (SAS Institute, Cary, NC) and Microsoft Excel v.2003 (Microsoft Corp., Redmond, WA) software, using a Type I error rate $(\alpha)$ of 0.05 , and included summary statistics and analysis of variance (ANOVA) to test for differences between main factors, interactions, and treatment combination effects.

\section{Results and Discussion}

Means and standard deviations for the main effects examined are provided in Table 1. Treatment combination effects are shown in Figures 2-5. Most interactions were statistically significant, so treatment combinations are discussed in depth.

\subsection{Color Properties}

Results indicated little variation in Hunter L brightness due to either time or ethanol concentration. As the number of extractions increased, the DDGS became slightly brighter, as determined by visual inspection. It appears that the DDGS material had additional time to release oils and carotenoids the longer the DDGS was soaked in solvent, because the solvent was able to more effectively penetrate the particles. Another difference was observed between brightness and particle size. The smaller particle size $(0.329 \mathrm{~mm})$ was consistently brighter than the larger particle size $(0.384 \mathrm{~mm})$. This difference was probably due to increased DDGS surface area exposure to the ethanol extraction process, which was a result of the milling process. An increased quantity of oils and carotenoids were thus extracted, resulting in a brighter end product. Untreated (i.e., non-extracted), unmilled, raw DDGS had a slightly lower (i.e., darker) Hunter L value (45.98), while untreated, milled DDGS $(0.329 \mathrm{~mm})$ had a higher (brighter) Hunter L value (51.59). Thus, untreated, raw DDGS became much brighter after simply grinding to a smaller particle size. It is likely that the Maillard browning that occurred during drying was near the particle surfaces, and once particles were milled, it was observed that lighter interior color was exposed. Once the outer and inner surfaces were mixed together, the grain mixture as a whole became brighter. Abdel-Aal and Sosulski (2001) found similar results when they used an alkaline hydrogen peroxide color 
removal technique on wheat fiber and wheat protein fractionsfrom stillage. After bleaching, they wet milled the solids $(0,1,2$, or 3 times) to a particle size of $210 \mathrm{~m}$. The Hunter L values steadily increased as the number of millings increased.

Hunter a values indicate the amount of green (-) to red (+) pigment in a given material. Results showed that as time and number of extractions increased, a slight decreasing trend in Hunter a values was found. An increased amount of extractions and extended time in ethanol produced DDGS that had reduced red pigments. Another significant difference was due to particle size: as particle size decreased, so did the quantity of red pigments. Again, this was likely due to the increased surface area was accessible for oils and carotenoids to leave. Lastly, as the ethanol concentration increased, DDGS with slightly increased red pigments resulted. Abdel-Aal et al. (1996) bleached wheat distillers grains with alkaline hydrogen peroxide. As they increased the solvent concentration, Hunter a values decreased, indicating that stronger solutions were able to extract additional red pigments. Furthermore, the increase in Hunter a values may be due to an increased percentage of lighter pigments being removed instead of darker pigments.

Hunter b values quantify the amount of blue (-) to yellow (+) pigment in a given sample. Ethanol concentration did not significantly impact Hunter $b$ values. Perhaps the ethanol concentration had little effect on extracting pigments with these colors. However, as time and number of extractions increased, a slight decrease of yellow pigments could be found. An increased quantity of extractions and additional time to be saturated created DDGS that was slightly less yellow. On the other hand, as particle size decreased, an increase in yellow pigments was found. Abdel-Aal and Sosulski (2001) also found similar trends as their alkaline hydrogen peroxide-treated wheat fiber was milled to smaller particle sizes, their Hunter $b$ values increased. They found that water and oil absorption increased as the quantity of millings and concentration of total dietary fiber also increased. Perhaps the smaller sized DDGS $(0.329 \mathrm{~mm})$ was absorbing more oils back into the grain due to increased surface area.

The 457 Brightness Index is a color indicator of a material's brightness compared to the relative brightness of paper. This variable was chosen as an additional index to quantify carotenoid reduction and color removal ability of the ethanol extraction process. As time and number of extractions increased, so did 457 brightness. The longer treatment time and increased extractions allowed additional time for the release of darker pigments. Smaller particles were brighter, which was likely caused by increased surface area. The Maillard browning on surfaces was probably disrupted through the grinding process.

Lastly, Gardner $10 \mathrm{~mm}$ and $20 \mathrm{~mm}$ indices were also analyzed. These values are often used to describe the yellowness of objects, often used for color of oils, varnishes, fatty acids, and resin solutions (HunterLab Manual, 1998). Results indicated that after ethanol extraction, DDGS samples exhibited lower index values compared to original, unprocessed material. This shows that the carotenoids and oils extracted from the DDGS ultimately decreased the yellow pigmentation of the resulting DDGS. As the amount of extractions and time increased, Gardner values steadily decreased. Also, as the particle size decreased, Gardner values also decreased. This indicated that smaller particle sizes lost yellow pigments due to increased surface area.

Table 1 illustrates main effects for physical and chemical properties due to extraction conditions. It is important to note that the physical property main effects arguably show statistically significant differences for various independent variables. Particle size, quantity of extractions, and time had the most significant effects on pigment levels, however ethanol concentration had little effect. 
Table 1. Main effects on physical and chemical properties due to extraction conditionsfor a given main effect, differing letters between levels for a given property signify significant differences $(\mathrm{P}<0.05, \mathrm{LSD})(\mathrm{n}=2$ for all properties)

\begin{tabular}{|c|c|c|c|c|c|c|c|c|c|c|c|c|c|c|}
\hline & \multicolumn{2}{|l|}{$\begin{array}{l}\mathbf{L} \\
\end{array}$} & \multirow{2}{*}{\multicolumn{2}{|c|}{$\begin{array}{l}\mathrm{a} \\
\text { Mean }\end{array}$}} & & \multicolumn{3}{|l|}{ b } & \multicolumn{2}{|c|}{457 Brightness } & \multicolumn{2}{|c|}{ Gardner 10mm } & \multicolumn{2}{|c|}{ Gardner 20mm } \\
\hline & Mean & St. Dev. & & & St. Dev. & Mean & & St. Dev. & Mean & St. Dev. & Mean & St. Dev. & Mean & St. Dev. \\
\hline \multicolumn{15}{|l|}{ Untreated } \\
\hline Raw DDGS $(0.384 \mathrm{~mm})$ & 45.98 & 0.49 & 9.27 & & 0.09 & 22.09 & & 0.22 & 6.02 & 0.15 & 9.08 & 0.04 & 7.50 & 0.00 \\
\hline Milled DDGS $(0.329 \mathrm{~mm})$ & 51.59 & 0.78 & 7.62 & & 0.18 & 22.57 & & 0.32 & 9.30 & 0.37 & 8.17 & 0.05 & 6.65 & 0.08 \\
\hline \multicolumn{15}{|l|}{ Treated } \\
\hline \multicolumn{15}{|l|}{$\underline{\text { Size }(\mathrm{mm})}$} \\
\hline$\overline{0.329}$ & $47.78 \mathrm{~A}$ & 0.87 & 6.36 & & 0.29 & $18.76 \mathrm{~A}$ & & 0.63 & $9.66 \mathrm{~A}$ & 0.66 & $7.48 \mathrm{~A}$ & 0.21 & $6.01 \mathrm{~A}$ & 0.20 \\
\hline 0.384 & $45.70 \mathrm{~B}$ & 0.82 & 6.88 & & 0.30 & $18.35 \mathrm{~B}$ & & 0.57 & $8.56 \mathrm{~B}$ & 0.62 & $7.71 \mathrm{~B}$ & 0.23 & $6.22 \mathrm{~B}$ & 0.22 \\
\hline \multicolumn{15}{|l|}{$\underline{\text { Time }(\min )}$} \\
\hline$\overline{30}$ & 46.68 & 1.35 & 6.68 & & 0.43 & $18.63 \mathrm{~A}$ & & 0.63 & $9.02 \mathrm{~A}$ & 0.94 & $7.63 \mathrm{~A}$ & 0.28 & $6.15 \mathrm{~A}$ & 0.26 \\
\hline 60 & 46.78 & 1.36 & 6.62 & & 0.35 & $18.58 \mathrm{~A}$ & & 0.61 & $9.12 \mathrm{AB}$ & 0.80 & $7.61 \mathrm{AB}$ & 0.22 & $6.12 \mathrm{AB}$ & 0.21 \\
\hline 90 & 46.77 & 1.31 & 6.56 & & 0.38 & $18.46 \mathrm{~B}$ & & 0.65 & $9.20 \mathrm{~B}$ & 0.78 & $7.55 \mathrm{~B}$ & 0.24 & $6.08 \mathrm{~B}$ & 0.22 \\
\hline \multicolumn{15}{|l|}{ Number of Extractions } \\
\hline$\overline{1}$ & $46.54 \mathrm{~A}$ & 1.35 & 6.69 & & 0.39 & $18.79 \mathrm{~A}$ & & 0.57 & $8.78 \mathrm{~A}$ & 0.83 & $7.70 \mathrm{~A}$ & 0.25 & $6.22 \mathrm{~A}$ & 0.23 \\
\hline 2 & $46.73 \mathrm{~A}$ & 1.28 & 6.63 & & 0.37 & $18.49 \mathrm{~B}$ & & 0.62 & $9.15 \mathrm{~B}$ & 0.71 & $7.58 \mathrm{~B}$ & 0.22 & $6.10 \mathrm{~B}$ & 0.20 \\
\hline 3 & $46.96 \mathrm{~B}$ & 1.36 & 6.55 & & 0.40 & $18.38 \mathrm{~B}$ & & 0.64 & $9.40 \mathrm{C}$ & 0.88 & $7.51 \mathrm{C}$ & 0.24 & $6.03 \mathrm{C}$ & 0.23 \\
\hline \multicolumn{15}{|l|}{ Concentration $(\mathrm{mL} / \mathrm{g})$} \\
\hline$\overline{5}$ & 46.65 & 1.23 & 6.58 & & 0.41 & 18.54 & & 0.61 & 9.05 & 0.81 & 7.60 & 0.26 & 6.12 & 0.24 \\
\hline 10 & 46.84 & 1.37 & 6.61 & & 0.34 & 18.57 & & 0.61 & 9.17 & 0.75 & 7.59 & 0.20 & 6.11 & 0.19 \\
\hline \multirow[t]{3}{*}{15} & 46.74 & 1.41 & 6.66 & & 0.42 & 18.57 & & 0.68 & 9.11 & 0.95 & 7.60 & 0.29 & 6.13 & 0.27 \\
\hline & \multicolumn{2}{|c|}{ Protein $(\% \mathrm{db})$} & \multicolumn{3}{|c|}{ Lipid (\% db) } & \multicolumn{3}{|c|}{ Pigments (\% db) } & & & & & & \\
\hline & Mean & St. Dev. & Mean & & St. Dev. & Mean & & St. Dev. & & & & & & \\
\hline \multicolumn{15}{|l|}{ Untreated } \\
\hline Raw DDGS $(0.384 \mathrm{~mm})$ & 30.25 & 0.09 & 10.57 & & 1.57 & 3.68 & & 0.01 & & & & & & \\
\hline Milled DDGS $(0.329 \mathrm{~mm})$ & 30.23 & 0.36 & 10.61 & & 1.11 & 4.54 & & 0.06 & & & & & & \\
\hline \multicolumn{15}{|l|}{ Treated } \\
\hline \multicolumn{15}{|l|}{$\underline{\text { Size }(\mathrm{mm})}$} \\
\hline$\overline{0.329}$ & 39.80 & 1.28 & 1.91 & A & 1.65 & 2.59 & A & 0.50 & & & & & & \\
\hline 0.384 & 39.81 & 1.06 & 2.39 & B & 1.39 & 2.11 & B & 0.58 & & & & & & \\
\hline \multicolumn{15}{|l|}{ Time (min) } \\
\hline$\overline{30}$ & $39.46 \quad$ A & 1.31 & 2.36 & A & 1.61 & 2.47 & A & 0.51 & & & & & & \\
\hline 60 & $39.96 \mathrm{AB}$ & 1.07 & 2.09 & B & 1.53 & $2.34 \mathrm{~A}$ & $\mathrm{AB}$ & 0.58 & & & & & & \\
\hline 90 & $39.99 \quad$ B & 1.07 & 2.01 & B & 1.50 & 2.23 & B & 0.67 & & & & & & \\
\hline \multicolumn{15}{|l|}{ Number of Extractions } \\
\hline$\overline{1}$ & $39.13 \mathrm{~A}$ & 0.67 & 3.80 & A & 1.42 & 2.86 & A & 0.52 & & & & & & \\
\hline 2 & 39.72 B & 1.39 & 1.65 & B & 0.81 & 2.26 & B & 0.47 & & & & & & \\
\hline 3 & $40.56 \mathrm{C}$ & 0.88 & 1.00 & $\mathrm{C}$ & 0.40 & 1.93 & $\mathrm{C}$ & 0.36 & & & & & & \\
\hline Concentration $(\mathrm{mL} / \mathrm{g})$ & & & & & & & & & & & & & & \\
\hline$\overline{5}$ & 39.71 & 1.01 & 3.03 & A & 1.91 & 2.54 & A & 0.71 & & & & & & \\
\hline 10 & 39.99 & 1.13 & 1.91 & B & 1.20 & 2.30 & B & 0.51 & & & & & & \\
\hline 15 & 39.72 & 1.36 & 1.51 & $\mathrm{C}$ & 0.94 & 2.20 & B & 0.51 & & & & & & \\
\hline
\end{tabular}



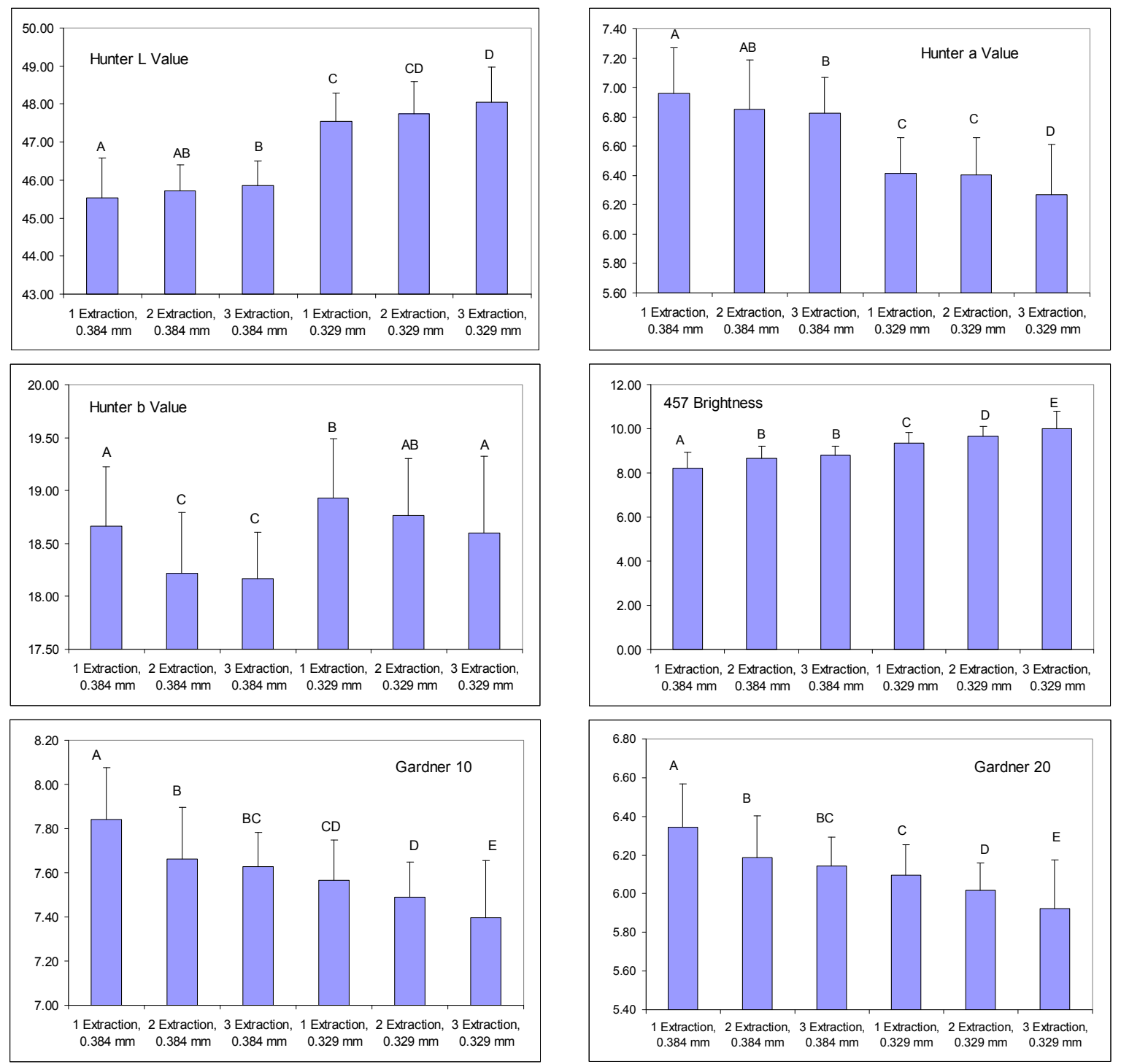

Figure 2. Treatment combination effects due to number of extractions and particle size on resulting DDGS color parameters

Hunter L showed increased brightness with increased extractions; Hunter a showed decreased red pigments with increased extractions; Hunter $\mathrm{b}$ showed decreased yellow pigments with increased extractions; 457 Brightness showed increased brightness with increased extractions; Gardner 10 showed decreased values with increased extractions; Gardner 20 showed decreased values with increased extractions. Error bars represent \pm 1 standard deviation. Differing letters signify significant differences between treatment combinations $(\mathrm{P}<0.05, \mathrm{LSD})$

Figure 2 highlights significant differences between treatment combination effects for physical properties. Hunter $\mathrm{L}$ and 457 Brightness values show a steady increasing trend in brightness as the number of extractions increased. The DDGS $(0.329 \mathrm{~mm})$ appeared to have enhanced brightening ability due to increased surface area. Hunter a values slightly decreased, indicating a drop in red pigments. The larger particle size demonstrated a higher initial red pigment content than smaller particles. Hunter $b$ values exhibited steady decreasing trends which resulted in less yellow pigments. Finally, both Gardner values had decreasing trends, meaning that additional yellow pigments were lost as the quantity of ethanol extractions increased.

\subsection{Chemical Properties}

\subsubsection{Protein}

Variables such as particle size and concentration of ethanol appeared to have no effect on protein content (Table 1). However, an increasing trend indicated that as extractions and time of agitation increased, a higher total protein content (\% dry basis) resulted. As the DDGS was increasingly extracted, more lipids and pigments were 
removed. Thus a shift in proportions occurred, increasing carbohydrate and protein percentages, while decreasing lipid percentage. Park et al. (1997) found similar results when investigating ethanol extraction of corn gluten meal (CGM). As the quantity of extractions increased, a steady increase in protein was also found. CGM had a higher dispersibility in ethanol; therefore carotenoids were rapidly extracted into the ethanol, leaving behind protein.

Amino acids are the building blocks of proteins and typically contain the same structural components: carbon center, carboxyl group, amino group, and a side chain. An amino acids polarity is determined by characteristics of the side chain. Non-polar side chains contain an aliphatic or aromatic group, which results in a hydrophobic amino acid. Polar side chains contain a variety of functional groups that provide an electron pair that will bond to water or other similar molecules. Protein solubility can also be explained by dividing proteins into two groups: globular proteins (polar) and fibrous proteins (non-polar) (Boyer, 2002). It is reasonable to assume that the non-polar fibrous proteins from DDGS did not become soluble in the polar ethanol solvent. Therefore, these proteins remained intact in the processed DDGS, not removed by the extraction.

Figure 3 shows trends found among treatment combinations, and the effects on protein content. A steady increase in protein content resulted from increased processing time and number of extractions. Protein was highest after the third extraction, due to the proportional shift in percentages. As lipid content decreased, carbohydrate and protein contents naturally increased.

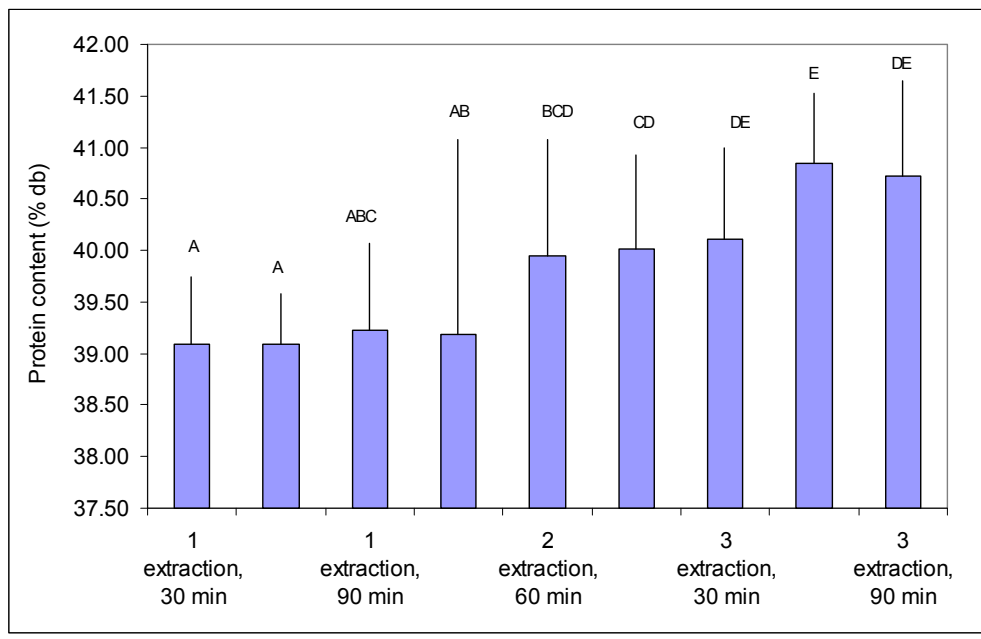

Figure 3. Treatment combination effects on resulting DDGS protein levels due to extraction time and number of extractions

As the number of extractions increased, the protein content increased because the lipid percentage decreased. Error bars represent \pm 1 standard deviation. Differing letters signify significant differences between treatment combinations $(\mathrm{P}<0.05, \mathrm{LSD})$.

\subsubsection{Lipids}

Data analysis revealed many trends; however, statistical analysis proved difficult to discern differences between treatment combinations, due to many overlapping mean values. Particle size, number of extractions, and ethanol concentration were statistically significant, and different from each other. Time was also statistically significant, but arguably little difference truly existed between treatments. As time, number of extractions, and ethanol concentration increased, the lipid content steadily decreased. These trends are reasonable as oils, lipids, and carotenoids are soluble in ethanol. Therefore the longer the DDGS is saturated and agitated in ethanol, the more lipids will be extracted. Smaller sized DDGS particles should contain less final lipid, as surface area is increased, allowing the interior of the particles to become more saturated with ethanol, thereby enhancing extraction. Park et al. (1997) had similar results when extracting corn gluten meal with ethanol, as ethanol extraction increased, the percentage of lipid remaining steadily decreased. The first extraction removed $20 \%$ of lipids; however a second extraction removed an additional $62 \%$ of lipids, so that in total, $82 \%$ of the original lipids were removed.

Lipids that typically make up less than $1 \%$ of the fresh weight of many fruits and vegetables (i.e. phospholipids and glycolipids) are polar. Cereals can also accumulate an increased amount of polar lipids, usually from the 
endosperm. These lipids can aid gluten development for flours that also contain gluten-forming proteins (Fennema, 1996). It is the carboxyl functional group (-COOH) that allows the fatty acid to be considered polar. The degree of solubility a lipid will have is affected by its structure. For example, solubility decreases with increasing lipid chain length (Boyer, 2002). Generally, polar reactants will dissolve in polar solvents. Therefore, it is reasonable that those polar lipids found in DDGS became soluble in the ethanol solvent, which was then extracted

Figure 4 illustrates trends found among treatment combinations for final DDGS lipid content. Major trends indicated that lipid content decreased with increasing time, ethanol concentration, and number of extractions. These trends were similar, regardless of particle size; however DDGS $(0.329 \mathrm{~mm})$ had a lower final lipid content. Untreated DDGS had a lipid content of $10.57 \%$ (db-dry basis) while untreated milled DDGS (0.329 mm) contained $10.61 \%(\mathrm{db})$, indicating very little difference in initial lipid content.

\subsubsection{Pigments}

As time, number of extractions, and ethanol concentration increased, a decrease in the percentage of pigments was found. These findings were similar to the trends found in lipid content. However, as particle size decreased, the quantity of pigment increased. Based upon the Hunter lab color spectrum, as yellow pigments are removed the entire color spectrum is shifted towards darker colors, including red.

Carotenoids are one of nature's most abundant pigments, which are typically yellow to orange in color. Corn, in particular, contains the two carotenoids: lutein and zeaxanthin. Carotenoids play a large role in the human diet by serving as a precursor of vitamin A. Research has found carotenoid concentration to be linked to the quantity of light exposure that particular plant receives. All classes of carotenoids are lipophilic, meaning they are soluble in oils and organic solvents such as ethanol. They can also lose color by becoming oxidized (Fennema, 1996). It is reasonable to assume they became soluble in the ethanol solvent and were removed through the extraction process during experimentation. 


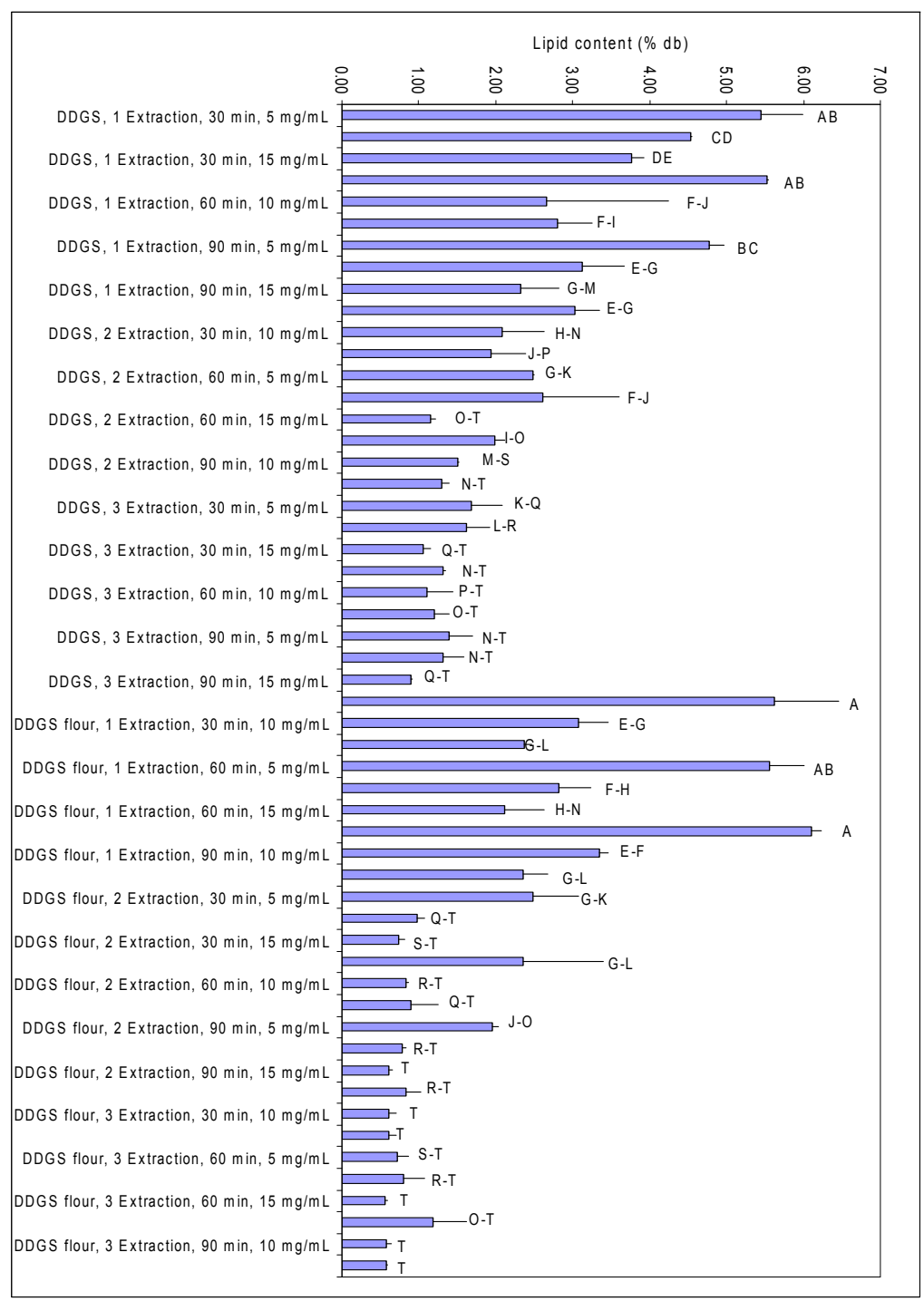

Figure 4. Treatment combination effects on resulting lipid content levels due to particle size, number of extractions, time, and extraction concentration. As the number of extractions increased a steady decrease in lipid content occurred. More extractions resulted in increasingly efficient removal of lipids. Error bars represent \pm 1 standard deviation

Figure 5 illustrates trends among treatment combinations for total pigment retained in the DDGS. Similar to Figure 4, two main decreasing trends are found. Total pigment retained decreased when time, ethanol concentration, and number of extractions increased. Particle size had a slight effect, as DDGS $(0.329 \mathrm{~mm}) \mathrm{had}$ somewhat higher total pigment quantities among the treatment combinations. Pigment content of raw, untreated DDGS was $3.68 \%(\mathrm{db})$, while untreated milled DDGS $(0.329 \mathrm{~mm})$ was $4.54 \%(\mathrm{db})$; pigment changes were due to the effect of grinding alone. Upon completion of ethanol extractions, pigment contents ranged from $1.93-2.86 \%$ (db).

\section{Conclusions}

Overall, physical and chemical data indicated a reduction in oils and carotenoid content due to extraction with ethanol. The number of extractions was the only independent variable that consistently had a significant effect on the dependent variables. The DDGS became brighter, showed a reduction in red and yellow pigments, enhanced protein content, and removed a substantial amount of lipids and pigments as the number of extractions increased. The amount of time the DDGS remained in the ethanol also resulted in many significant differences. Red and yellow pigments decreased, while DDGS brightness increased. Also, protein content increased while lipid and 
pigment concentrations decreased. Particle size also affected the extraction results. Smaller particles exhibited a reduction in red pigments, an increase in yellow pigments, and an overall increase in brightness. They also contained more pigments, but a reduced amount of lipids. Ethanol concentration had a small impact on pigment extraction. Color analysis showed ethanol extraction to be a moderately effective bleaching technique for DDGS materials. Chemical property data indicated that the treatments were extremely effective in reducing lipidand pigment values, while increasing protein percentages. Altering the chemical composition will alter its value to the end user, however. Carotenoids that remain in DDGS material may offer many health benefits to consumers. Carotenoids contain superior antioxidant protection against free radical tissue damage, and are a valuable nutraceutical.

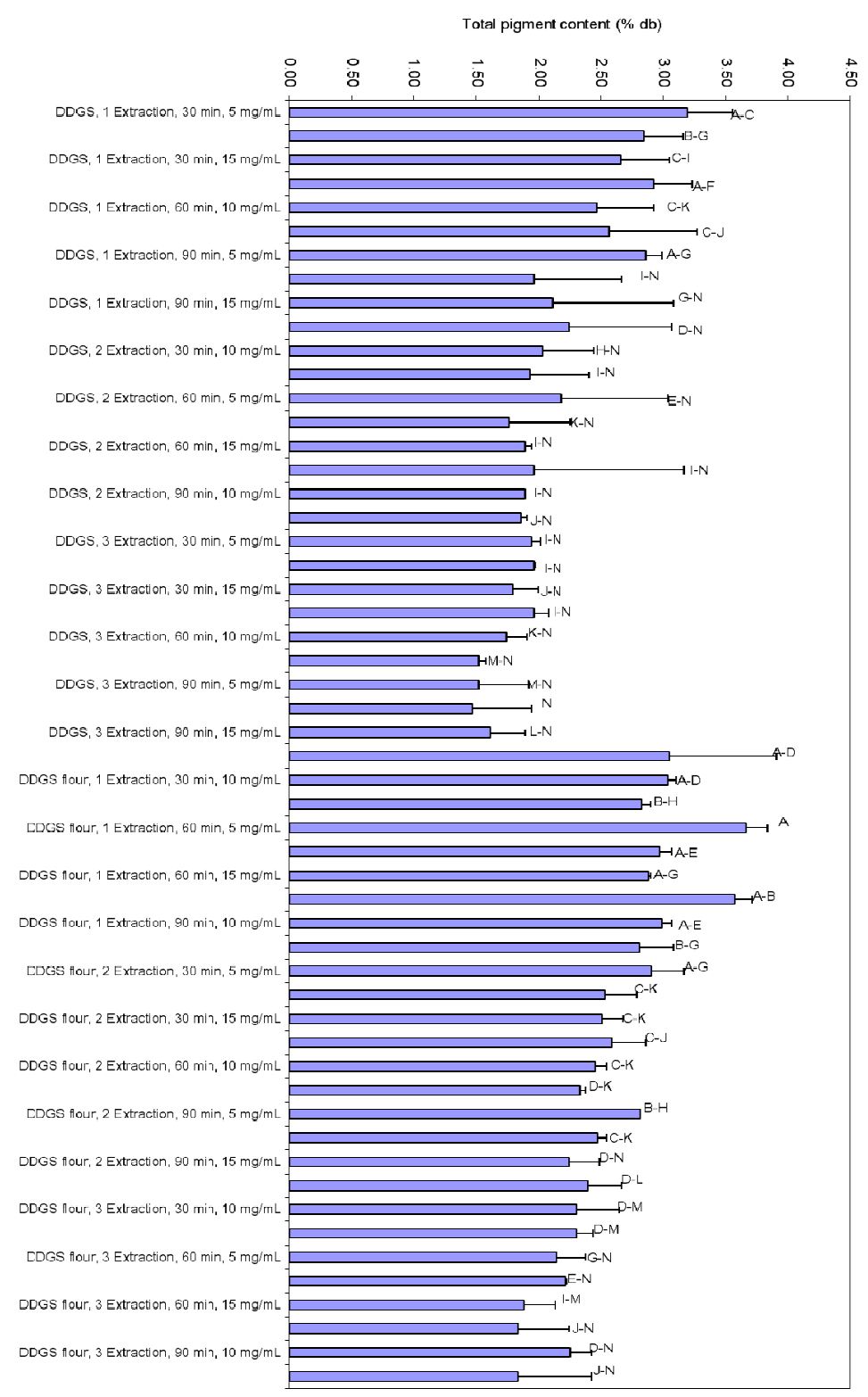

Figure 5. Treatment combination effects on resulting total pigment levels due to particle size, number of extractions, time, and extraction concentration. As the quantity of extractions increased, the pigment content decreased until diminished returns occurred. Certain treatment combinations showed that the third extraction was not as efficient in the removal of pigments. Error bars represent \pm 1 standard deviation

\section{References}

AACC. (2000). Approved Methods (10th ed.). St. Paul, MN: American Association of Cereal Chemistry. 
Abdel-Aal, E. S. M., Sosulski, F. W., \& Sokhansanj, S. (1996). Bleaching of Wheat Distillers' Grains and its Fibre and Protein Fractions with Alkaline Hydrogen Peroxide. Lebensm.-Wiss. u.-Technol., 29(3), 210-216. http://dx.doi.org/10.1006/fstl.1996.0031

Abdel-Aal, E. S. M., \& Sosulski, F. W. (2001). Bleaching and Fractionation of Dietary Fiber and Protein from Wheat-Based Stillage. Lebensm.-Wiss. u.-Technol., 34(3), 159-167. http://dx.doi.org/10.1006/fstl.2000.0741

AOAC. (2003). Fat (crude) or ether extract in animal feed. Official Methods of Analysis of AOAC International, (17th ed.). The Association: Gaithersburg, MA.

Arora, S. K., \& McFarlane, S. I. (2005). Review: The case for low carbohydrate diets in diabetes management. Nutrition \& Metabolism, 2(16), 1-9. http://dx.doi.org/10.1186/1743-7075-2-16

Belyea, R. L., Rausch, K. D., \& Tumbleson, M. E. (2004). Composition of corn and distillers dried grains with solubles from dry grind ethanol processing. Bioresource Technology, 94, 293-298. http://dx.doi.org/10.1016/j.biortech.2004.01.001

Boyer, R. (2002). Concepts in Biochemistry (2nd ed.) (pp. 70-94 and 208-240). Thomson Learning, Inc. United States.

Chang, D., Hojilla-Evangelista, M. P., Johnson, L. A., \& Myers, D. J. (1995). Economic-engineering assessment of sequential processing of corn. Transactions of the ASAE., 38(4), 1129-1138.

Chen, L. F., \& Hoff, J. E. (1987). Grain extraction milling U.S. Patent No. 4,716, 218.

Chien, J. T., Hoff, J. E., \& Chen, L. F. (1988). Simultaneous dehydration of $95 \%$ ethanol and extraction of crude oil from dried ground corn. Cereal Chem, 65(6), 484-486.

Chien, J. T., Hoff, J .E., Lee, M. J., Lin, H. M., Chen, Y. J., \& Chen, L. F. (1990). Oil extraction of dried ground corn with ethanol. Chemical Engng. J., 43, B103-B113. http://dx.doi.org/10.1016/0300-9467(90)80017-7

Dien, B. S., Bothast, R. J., Nichols, N. N., \& Cotta, M. A. (2003). The U.S. corn ethanol industry: an overview of current technology and future prospects. In The Third International Starch Technology Conference-Coproducts Program Proceedings. In M. Tumbleson, V. Singh, \& K. Rausch (Eds.), 2-4 June, 2003, University of Illinois, pp. 10-21.

Fennema, O. R. (1996). Food Chemistry (3rd ed.), In O. R. Fennema (Ed.), (pp. 218-220; 394-424). New York: Marcel Dekker Inc.

Hojilla-Evangelista, M. P., Johnson, L. A., \& Myers, D. J. (1992). Sequential extraction processing of flaked whole corn: Alternative corn fractionation technology with ethanol production. Cereal Chem., 69(6), 643-647.

Hunter Lab. (1998). The ASTM D6166 Gardner Index. Insight on Color. 10(1) Rev. 03/05.

Hunter Associates Laboratory. (2002). Universal Software User's Manual, Version 2.5.Reston, VA: Hunter Laboratory Associates.

Jaques, K. A., Lyons, T. P., \& Kelsall, D. R. (2003). The Alcohol Textbook. Nottingham, UK: Nottingham University Press.

Lee, A., \& Newman, J. (2003). Celiac diet: Its impact on quality of life. Journal of the American Dietetic Association, 103(11), 1533-1535. http://dx.doi.org/10.1016/j.jada.2003.08.027

Liu, K., \& Rosentrater, K. A. (2011). Distillers Grains: Production, Properties, and Utilization. Boca Raton, FL: CRC Press.

Mahan, L. K., \& Escott-Stump, S. (2004). Krause's Food, Nutrition, \& Diet Therapy (11th ed.). Philadelphia, PN: Saunders Press.

Park, H., Flores, R. A., \& Johnson, L. A. (1997). Preparation of fish feed ingredients: Reduction of carotenoids in corn gluten meal. J. Agric. Food Chem, 45(6), 2088-2092.http://dx.doi.org/10.1021/jf960972j

Rausch, K. D., \& Belyea, R. L. (2006). The future of coproducts from corn processing. Applied Biochemistry and Biotechnology, 128(1), 47-89. http://dx.doi.org/10.1385/ABAB:128:1:047

RFA. (2013). U.S. Fuel Ethanol Industry Biorefieneries and Production Capacity. Renewable Fuels Association. Washington DC. Retrieved July 31, 2013, from http://www.ethanolrfa.org/industry/locations/

Rosentrater, K. A., \& Krishnan, P. G. (2006). Incorporating distillers grains in food products. Cereal Foods World, 51(2), 52-60. 
Rosentrater, K. A., \& Muthukumarappan, K. (2006). Corn ethanol coproducts: generation, properties, and future prospects. International Sugar Journal, 108(1295), 648-657.

Saunders, J. A., \& Rosentrater, K. A. (2009). Properties of solvent-extracted low-oil corn distillers dried grains with solubles. Biomass and Bioenergy, 33, 1486-1490. http://dx.doi.org/10.1016/j.biombioe.2009.07.004

Saunders, J. A., Rosentrater, K. A., \& Krishnan, P. G. (2007). Potential bleaching techniques for use in distillers grains. ASABE Paper No. 076065. St. Joseph, MI: ASABE.

Shurson, G. C., Spiehs, M. J., \& Whitney, M. (2004). The use of maize distiller's dried grains with solubles in pig diets. Pig News and Information, 25(2), 75N-83N.

Singh, N., \& Cheryan, M. (1998). Extraction of oil from corn distillers dried grains with solubles. Transactions of the ASAE, 41(6), 1775-1777.

Spiehs, M. J., Whitney, M. H., \& Shurson, G. C. (2002). Nutrient database for distiller's dried grains with solubles produced from new ethanol plants in Minnesota and South Dakota. Journal of Animal Science, $80(10), 2639-2645$.

\section{Copyrights}

Copyright for this article is retained by the author(s), with first publication rights granted to the journal.

This is an open-access article distributed under the terms and conditions of the Creative Commons Attribution license (http://creativecommons.org/licenses/by/3.0/). 